\title{
The assessment of magnetic water treatment on formation calcium scale on reverse osmosis membranes
}

\author{
Alexey Andrianov* and Evgeny Orlov \\ Moscow State University of Civil Engineering, Yaroslavskoe shosse 26, Moscow, 129337, Russia
}

\begin{abstract}
Reverse osmosis is widely used technology for water desalination. The main problem with reverse osmosis is scaling which reduces the flow and selectivity of membranes. Normally, to prevent salt precipitation, chemicals are added to the feed water or water softening is applied. The literature data on the effect of magnetic treatment on the structure and properties of water and dissolved salts showed that there is no consensus among researchers on the mechanism of magnetic field action to prevent calcium deposits formation. The purpose of current work was to study the effect of magnetic water treatment on the rate of calcium carbonate scale formation on reverse osmosis membranes. Scaling tests were carried out on tap water using the spiral wound module with reverse osmosis membranes. Magnetic treatment efficiency was evaluated by comparison of scaling rate values (amount of calcium carbonate scales accumulated in membrane module) determined throughout experiments with and without magnetic device. The results obtained do not confirm the effect of magnetic treatment on calcium carbonate precipitate formation.
\end{abstract}

\section{Introduction}

Desalination by reverse osmosis is a wide spread technology for water treatment with elevated hardness and salinity. However, membranes are subjected to scaling with crystalline precipitates, mainly carbonate and calcium sulfate. Scaling reduces membrane flow and selectivity, and results in product water losses and frequent chemical cleaning. Normally, to prevent salt precipitation, chemicals are added to the feed water or water softening is applied. All pretreatment methods consume chemicals (acid, antiscalant or salt for ion-exchanger), which in turn elevates operating costs.

One of the interesting methods of non-chemical water treatment is magnetization of water solutions. There are many examples of effective application of magnetic water treatment in such industries as chemical, mining, metallurgical, production of construction materials, etc. [1-3]. There were attempts to use water magnetization in agriculture, stock farming and medicine. In a number of cases, a stable positive effect was reported, in others - no effect of magnetic treatment.

\footnotetext{
*Corresponding author: alexei-waterlab@yandex.ru
} 
The main reason for the variety of magnetized water applications is its important active role and wide presence in industrial and biological processes. Anti-scale magnetic water treatment has become the most popular for steam boilers, heat exchangers and other heat exchange devices [4-7]. The effect of magnetic field on aqueous solutions should reduce the scale rate of low soluble calcium and magnesium salts in pipes and on heat exchanger surfaces.

Generally, the magnetic water treatment method is passing water through the device at a certain velocity, where alternating magnetic fields (preferably orthogonal to water flow direction) are created. After such treatment, water loses its ability to deposit hardness salts in the form of scale, and these salts are crystallized as fine sludge easily carried away by the water flow.

Design of the simplest magnetic device is shown in Figure 1. The most magnetic water treatment devices use a series of magnets alternately arranged in different poles. When a fluid flow occurs, each element of the flow will intersect the magnetic lines of force, i.e., an external field will be variable in time, as well as in space for it. The flow of liquid through the high-intensity alternating magnetic field produces the greatest effect. The optimal operational requirements for efficient scale control are: minimal magnetic flux density $B=$ 0.1 to $0.2 \mathrm{~T}$, water flow velocity $v=1$ to $2 \mathrm{~m} / \mathrm{s}$, minimal exposure time $t=0.1$ to $0.2 \mathrm{~s}$ [8]. Magnetic field is created either by permanent magnets (simple or neodymium), or electromagnets (in large industrial units).

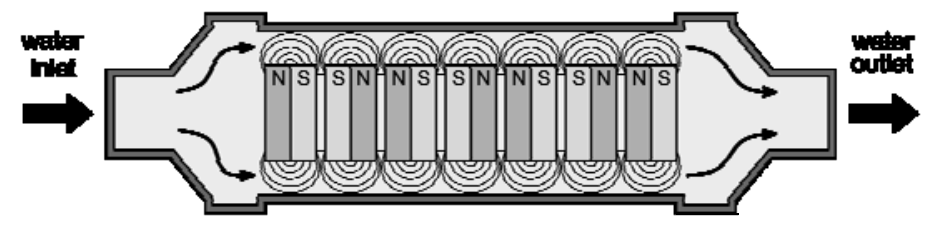

Fig. 1. Design of the simplest magnetic device.

Studies on water magnetization have shown that the greatest effect occurs in case of certain chemical water composition, i. e. water should have certain calcium carbonate hardness. The treatment of water with increased sulfate hardness did not give positive results [9]. All the factors that determine the possibility of obtaining supersaturated solutions, in particular presence of carbon dioxide in water, affect the results of magnetic treatment. With excessively high concentration of carbon dioxide, magnetic treatment effect deteriorates [2].

Still there is no final opinion on the mechanism how magnetic fields influence aqueous solutions. Various versions can be found in the literature, but there is no unified theory [1]. Hypotheses explaining the mechanism how magnetic field influences aqueous solutions can be divided into three groups: hypotheses that assume that magnetic fields influence only water structure [2]; hypotheses explaining the mechanism of how magnetic field influences ions in water [10]; hypotheses based on the effect of magnetic fields on those colloidal or suspended particles that feature magnetic susceptibility [3].

Practical use of water systems magnetic treatment is based on certain changes in their physical and physico-chemical properties. Intensification and stabilization of small initial changes in properties can occur with the help of intermediate mechanisms increasing many times these changes. In the most cases, such intensification is inherent to heterogeneous systems and their phase transitions. For example, the slightest stimulation of crystal formation can cause avalanche irreversible bulk crystallization, with all the process consequences. A slight decrease in hydration degree of solid particles surface under certain conditions can lead to their mass coagulation, as well as significant improvement in filtration, etc. 
Magnetic field may affect all the water system components: water structure itself, ions of dissolved substances, inclusions (colloidal particles, gas microbubbles, etc.). Change in the state and properties of each component may influence the entire system.

When water is treated with magnetic field, conditions are created for quicker formation of crystals in the water flow. Emerging crystalline nuclei serve as centers of crystallization, where low-soluble salts ions accumulate; these crystalline nuclei grow, precipitate and are removed from the system.

Ochkov V. F., after having conducted a series of experiments, suggested a possible explanation of the expected effect of magnetic treatment on water systems. He suggested that the observed changes in water properties are due to the presence of ferromagnetic iron impurities in water, which are formed in closed cooling water system [3, 11]. Ochkov conducted experiments with desalination plants, where water directed to a heat exchanger was previously passed through an electromagnetic device. Magnetization led to a qualitative change in the nature of scale formation. Instead of a dense layer of scale, finegrained sludge was formed; heat exchange surfaces remained clean. The magnetic device interior was covered with a uniform layer of sand-color scale, which turned black at places of an increased magnetic field gradient: these were traces of ferromagnetic impurities of water trapped by magnetic field.

After many years of research, Ochkov made a conclusion about the major role of the magnetic particles layer held in the gap of the magnetic device. First of all, this layer helps to remove some supersaturation of water as for solid or gaseous phase. Secondly, the smallest particles having sharp corners can form seed crystals, which further contribute to bulk crystallization of $\mathrm{CaCO}_{3}$ instead of scaling on the heat transfer surfaces.

Therefore, it can be stated that magnetic treatment of supersaturated water solutions containing ferromagnetic impurities can have a certain influence on scale formation and corrosion process in heat exchangers.

During water desalination by reverse osmosis, supersaturation of calcium carbonate and calcium sulfate also occurs, both in bulk water and near the membrane surface, in stagnant zones, where due to the effect of concentration polarization, concentration of salts may greatly exceed their concentration in feed water. The problem of membrane scaling can be partially solved, if we create conditions when crystalline sediment is formed not on the membrane, but in a water stream. Many authors confirm the effect of magnetic water treatment on behavior of aqueous solutions of calcium carbonate [3-9], but there are very few studies devoted to the effect of magnetized water on operation of reverse osmosis systems [12-15]. Some studies say there is no visible and stable effect after water magnetic treatment $[12,15]$; the others, on the contrary, say that action of magnetic field alters the properties of sediment $[13,14]$, reducing its amount and increasing the average membrane flux. Most authors, however, confirm that magnetic treatment changes the crystal structure and particle size of calcium carbonate scales.

In this paper, we decided to check the influence of magnetic treatment of water fed to the reverse osmosis unit on the rate of calcium carbonate scaling, which is the most common sediment in membrane modules.

\section{Materials and methods}

For magnetic water treatment, we used several commercial devices for domestic and industrial use (Figure 2). For further experiments, we selected MBC DN10 industrial device with a capacity of $0.9 \mathrm{~m}^{3} / \mathrm{h}$. The device housing is a piece of steel pipe, inside of which there is a set of cylindrical magnets (Figure 1). 


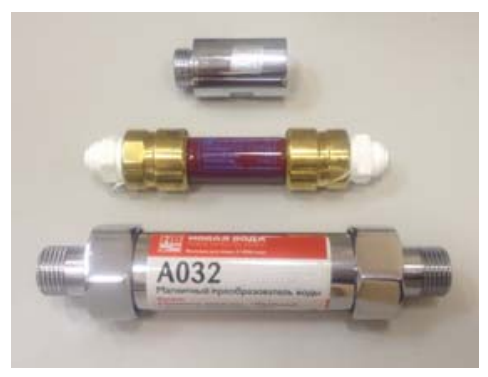

Fig. 2. Commercial devices for magnetic water treatment (from top to bottom): "New water" A030, MBC DN10, "New water" A032.

The tests were carried out on a laboratory plant (Figure 3) equipped with a reverse osmotic spiral wound membrane module, type RE1812-100 GPD (CSM). Source water is taken from the feed water tank 1 , and the pump 6 feeds it to the membrane module 4 . Operating pressure and flow rate of the concentrate are set by means of regulating valves 19 and 15 mounted on the pump bypass before the membrane module and on the concentrate line. The unit operates in a circulating mode: the concentrate is return to the feed water tank, and the filtrate is collected in the filtrate tank 2. Capacity of the feed water tank is 100 liters; capacity of the filtrate tank is 80 liters.

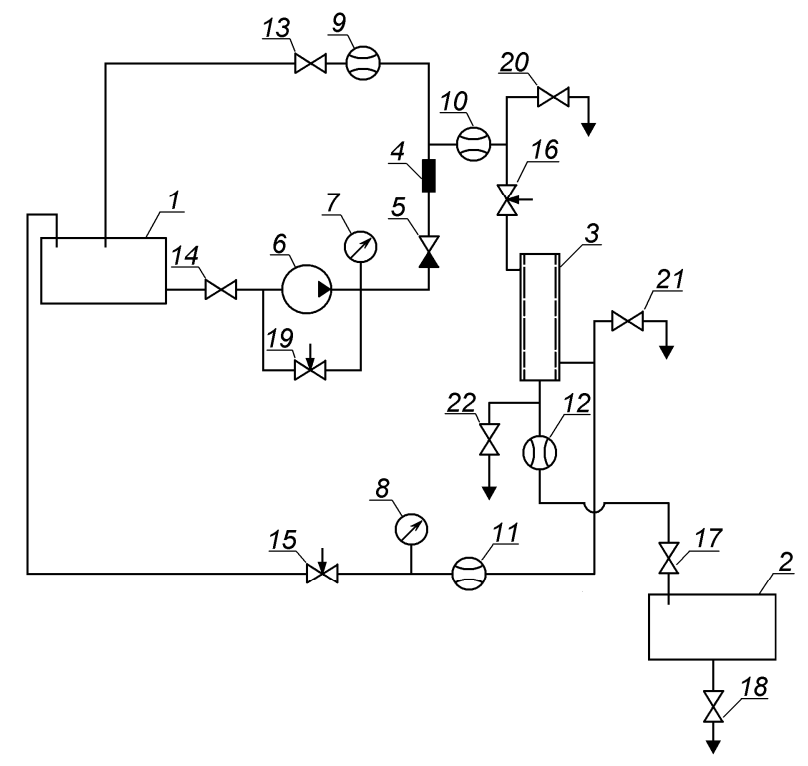

Fig. 3. Schematic diagram of laboratory membrane plant: 1 - Feed water tank, 2 - Filtrate tank, 3 Membrane module, 4 - Magnetic device, 5 - Check valve, 6 - Pump, 7, 8 - Manometers, 9-12 Rotameters, 13-22 - Valves.

The experimental procedure for determining calcium carbonate crystallization rates in membrane modules is described in detail in [16]. Since membrane module water flux is substantially less than the recommended flow rate through MBC DN10 device, so to maintain the required flow rate $\left(>0.9 \mathrm{~m}^{3} / \mathrm{h}\right)$, some part of feed water flow after magnetic treatment was returned to the feed water tank.

During the circulation experiments, water samples were taken at the following concentration factors (ratio of the concentrate volume to the feed solution volume): 1 (start of operation); 2; 3, 4 and 5. The samples were used to measure total salinity (using inoLab 
Cond 730 conductometer), total hardness and calcium content (titrimetrically with EDTA), pH (using HANNA pH 210 lab pH-meter), alkalinity (by titration with hydrochloric acid solution). During the experiment, the following operation parameters were monitored: pressure before and after the membrane module, concentrate and filtrate flow rates, and the circulating solution temperature.

\section{Results and discussion}

Results of the series of experiments are summarized in Table 1. Each test lasted from 3 to 3.2 hours, depending on the achieved concentration ratio $\mathrm{K}$. The amount of calcium carbonate scale accumulated in the membrane module was calculated as the difference between calcium ions amount in the source water at the beginning of the experiment and amount of these ions in the concentrate and filtrate at the end of the experiment.

The results of total hardness determination in circulating solution for tests No 1-4 is shown on Figure 4. Straight lines demonstrate calculated values of total hardness in the absence of scaling. The difference between actual and calculated value indicates the degree of scaling. The shape of the curves shows that, as the concentration is increased, the rate of calcium carbonate precipitation is slowed by the removal of precipitating ions from the solution. The maximum concentration ratio $(K=4$ or $K=5)$ have no influence on the effect of magnetic treatment. Feed water quality varied in different series of experiments, but also had no stable effect on the amount of $\mathrm{CaCO}_{3}$ accumulated in membrane module.

Table 1. Results of defining the amount of $\mathrm{CaCO}_{3}$ sediment accumulated in the membrane module.

\begin{tabular}{|c|c|c|c|c|c|c|}
\hline \multirow{2}{*}{$\begin{array}{l}\text { Test } \\
\text { No }\end{array}$} & \multirow{2}{*}{$\begin{array}{l}\text { Magnetic } \\
\text { treatment }\end{array}$} & \multirow{2}{*}{$\begin{array}{c}\text { Concentration } \\
\text { ratio } \mathrm{K}\end{array}$} & \multirow{2}{*}{$\begin{array}{c}\text { The amount of } \\
\mathrm{CaCO}_{3} \text { accumulated } \\
\text { in membrane module } \\
\left(\mathrm{mEq} \text { of } \mathrm{Ca}^{2+}\right)\end{array}$} & \multicolumn{3}{|c|}{ Feed water quality } \\
\hline & & & & $\begin{array}{c}\text { Total } \\
\text { hardness } \\
(\mathrm{mEq} / \mathrm{L})\end{array}$ & $\begin{array}{l}\text { Calcium } \\
(\mathrm{mEq} / \mathrm{L})\end{array}$ & $\begin{array}{l}\text { Alkalinity } \\
(\mathrm{mEq} / \mathrm{L})\end{array}$ \\
\hline 1 & - & 4 & 40.1 & 3.55 & 2.75 & 3.2 \\
\hline 2 & + & 4 & 40.0 & 3.3 & 2.6 & 3.0 \\
\hline 3 & - & 4 & 45.5 & 3.6 & 2.8 & 3.5 \\
\hline 4 & + & 4 & 37.6 & 3.2 & 2.5 & 3.3 \\
\hline 5 & - & 5 & 45.5 & 2.95 & 2.3 & 2.65 \\
\hline 6 & + & 5 & 21.5 & 2.65 & 2.1 & 2.5 \\
\hline 7 & - & 5 & 36.0 & 2.8 & 2.2 & 2.65 \\
\hline 8 & + & 5 & 39.7 & 2.7 & 2.1 & 2.6 \\
\hline
\end{tabular}
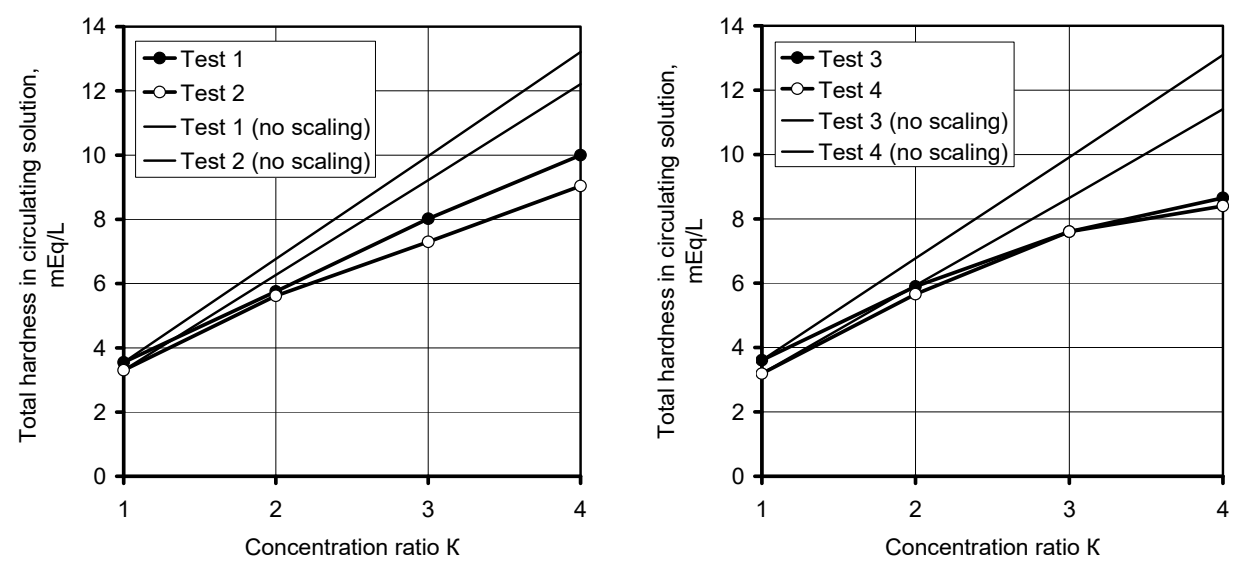

Fig. 4. Actual and calculated values of total hardness versus concentration ratio. 


\section{Conclusions}

Magnetic treatment of aqueous solutions is widely known in science and in practice, but still remains questionable due to the ambiguity and instability of the effect obtained. Magnetic treatment influence on behavior of low-soluble calcium salts solutions has been studied quite well, including operation of water heaters and heat exchange equipment. However, as for reverse osmosis units, this issue has not been studied enough.

The results of the experiments have shown that magnetic treatment of water supplied to the reverse osmosis unit does not have a significant effect on the calcium carbonate scaling rate. The effect of magnetic water treatment does not exceed the range of the obtained values of the scale amount and does not allow making any unambiguous conclusions. Based on the pilot tests of the water magnetic treatment device, we can state the main objectives of the following, more extensive studies: comparison of several different magnetic devices, application of model solutions simulating water with increased hardness, comparison of different modes of water treatment in a reverse osmosis unit, opening the magnetic device to check the presence of ferromagnetic particles in the flow section.

\section{References}

1. M.R. Powell, Skeptical Inquirer 22.1 (1998)

2. V.I. Klassen, Developments in Mineral Processing, Part B, Mineral Processing, 10771097 (Elsevier, N.Y., 1981)

3. V. Ochkov, J. Chudova, Proc. of 16th Int. Conf. on the Properties of Water and Steam (United Kingdom, 2013)

4. D. Dobersek, L. Crepinsek Lipus, D. Goricanec, J. Krope, Proc. of the 5th WSEAS Int. Conf. on Instrumentation, Measurement, Control, Circuits and Systems - IMCCAS 2005 (Cancun, Mexico, 2005)

5. M. Gryta, Separation and Purification Tech. 80, 2, 293-299 (2011)

6. C. Smith, P.P. Coetzee, J.P. Meyer, Water SA 29, 3, 231-236 (2003)

7. S.A. Parsons, S.J. Judd, T. Stephenson, S. Udol, B.L. Wang, Process Safety and Env. Protection 75, 2, 98-104 (1997)

8. L.C. Lipus, B. Acko, A. Hamler, Int. J. of Simulation Modelling 11, 3, 141-149 (2012)

9. F. Alimi, M. Tlili, M. Ben Amor, G. Maurin, C. Gabrielli, Adv. Materials Res., 554556, 649-656 (2012)

10. B. Guo, H. Han, F. Chai, Nonferrous Met. Soc. China 21, s494-s498 (2011)

11. O.I. Martynova, A.S. Kopylov, E.F. Tebenihin, V.F. Ochkov, Thermal Eng. 6, 67 (1979)

12. J.S. Baker, S.J. Judd, S.A. Parsons, Desalination 110, 1-2, 151-165 (1997)

13. C.V. Vedavyasan, Desalination 134, 105-108 (2001)

14. J. Li, J. Liu, T. Yang, C. Xiao, Water Research 41, 20, 4595-4610 (2007)

15. I. Goldie, M. Aziz, A.H. Abozrida, R.D. Sanderson, Anti-scaling studies on high $\mathrm{CaCO}_{3}$ waters in spiral-WRAP membrane systems, WRC Report No. 1593/1/08 (2008)

16. A.G. Pervov, Desalination 83, 77-118 (1991) 